\title{
VACTERL with hydrocephalus
}

INSERM

\section{Source}

INSERM. (1999). Orphanet: an online rare disease and orphan drug data base. VACTERL with hydrocephalus. ORPHA:3412

VACTERL is an acronym for Vertebral anomalies, Anal atresia, Congenital cardiac disease, Tracheoesophageal fistula, Renal anomalies, and Limb defects. VACT ERL associated with hydrocephalus has rarely been reported and is thought to be an autosomal recessive anomaly. The condition is described as a uniformly lethal or developmentally devastating disorder distinct from the VATER association. 